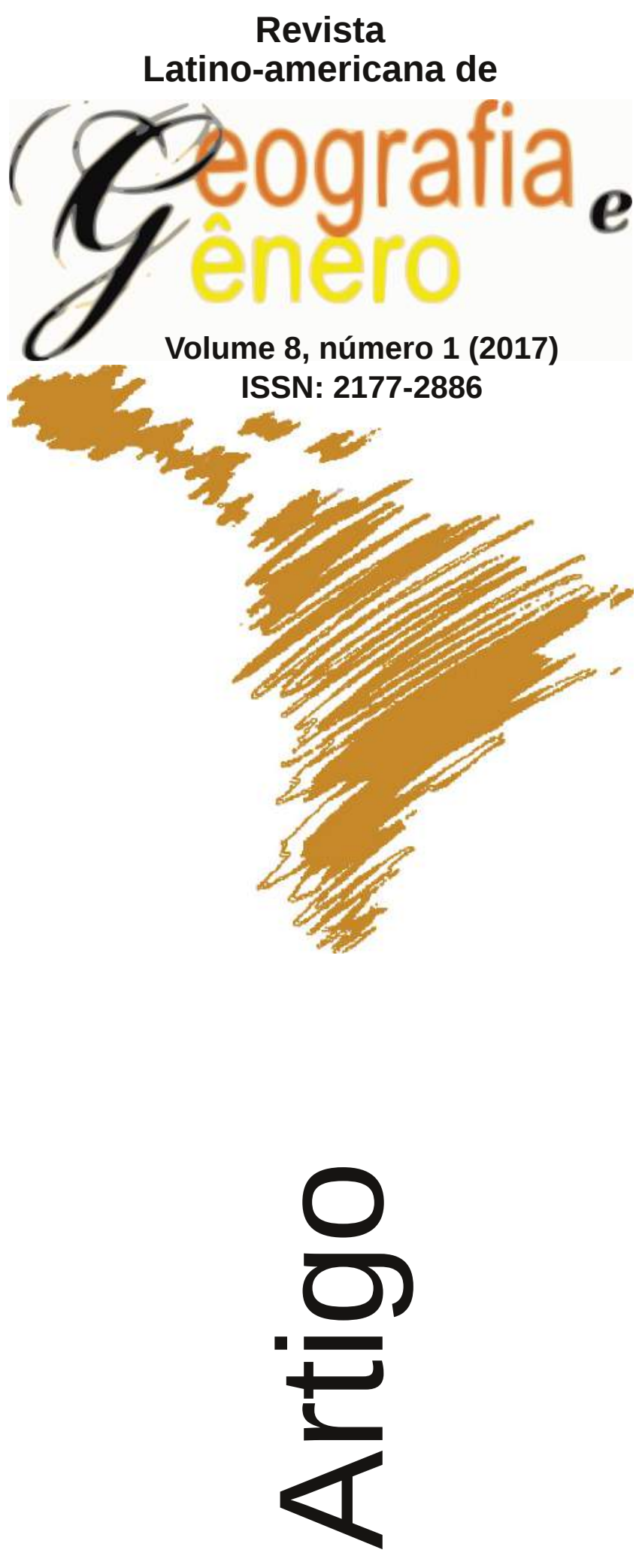

A Transexualidade em Questão em Serviços de Saúde Mental com Leitos Masculinos e Femininos do Rio Grande do Sul

La Transexualidad en Cuestión en los Servicios de Salud Mental con Camas Masculinas y Femeninas en Rio Grande do Sul

Question Transexuality in Mental Health Facilities with Male and Female Beds in Rio Grande do Sul

Cristiane Camponogara Baratto

Universidade Federal de Santa Maria - Brasil cristiane.cb@hotmail.com

Eliana Dable de Mello

Universidade Federal do Rio Grande do Sul - Brasil elianamello3@gmail.com

Lívia Zanchet

Universidade Federal do Rio Grande do Sul - Brasil liviazanchet@yahoo.com.br

Como citar este artigo:

BARATTO, Cristiane Camponogara; MELLO, Eliana Dable de; ZANCHET, Lívia. A Transexualidade em Questão em Serviços de Saúde Mental com Leitos Masculinos e Femininos do Rio Grande do Sul. Revista Latino Americana de Geografia e Gênero, v. 8 , n. 1, p. 333-353, 2017. ISSN 2177-2886.

Disponível em:

http://www.revistas2.uepg.br/index.php/rlagg 


\title{
A Transexualidade em Questão em Serviços de Saúde Mental com Leitos Masculinos e Femininos do Rio Grande do Sul
}

\author{
La Transexualidad en Cuestión en los Servicios de Salud Mental con Camas \\ Masculinas y Femeninas en Rio Grande do Sul
}

\section{Question Transexuality in Mental Health Facilities with Male and Female Beds in Rio Grande do Sul}

\section{Resumo}

Estudos apontam que a população LGBT vem alcançando maior visibilidade para suas questões, incluídas as de saúde mental. Apesar de avanços significativos com a criação da Política Nacional de Saúde LGBT, os serviços de saúde ainda costumam pensar suas práticas sem o conhecimento desta. Dessa forma, propusemos um processo reflexivo das equipes de uma internação psiquiátrica e de um CAPS AD III a respeito do atendimento a transexuais quando estes usuários necessitam de permanência noturna no serviço, onde os leitos são separados de forma binária masculino/feminino. Foram realizados grupos focais com cada equipe e a análise foi feita pelo Método Narrativo de Onocko-Campos. Foram extraídos oito temas para análise que são expostos neste artigo através de narrativas.

Palavras-Chave: Transexualidade; Leitos de Permanência Noturna; Saúde Mental.

\section{Resumen}

Los estudios muestran que la población LGBT ha logrado una mayor visibilidad de sus problemáticas, entre ellas la salud mental. A pesar de los avances significativos con la creación de la Política Nacional de Salud LGBT, los servicios de salud todavía piensan sus prácticas sin conocerla. Hemos propuesto un proceso de reflexión del equipo de un hospital psiquiátrico y de un CAPS AD III en relación a la atención de transexuales cuando el usuario necesita pernoctar en el servicio, donde las camas están separadas de forma binaria masculino/femenino. Se realizaron grupos focales con cada equipo y el análisis se realizó con el Método de Narrativo de Onocko-Campos. Ocho temas fueron extraídos para su análisis y se exponen en este artículo a través de narrativas.

Palabras-Clave: Transexualidad; Camas de Pernoctación; Salud Mental.

\section{Abstract}

Studies suggest that LGBT population's issues are becomig more visible, and this includes mental health. Despite significant advances due to the creation of the National LGBT Health Policy, in Brazil, health services often still think their practices without taking this policy in account. Thus, we proposed a reflection for the teams of a psychiatric hospital wing and of a CAPS AD III (Center for Psychossocial Attention - Alcohol and Drugs) regarding the assistance to transsexuals, whenever these users need an overnight stay in the facilities, where the beds are separated in male/female. Focus groups were conducted with each team and the analysis was done by the Onocko-Campos Narrative Method. Eight themes were chosen for analysis, and they are exposed in this article by means of narratives.

Keywords: Transsexuality; Hospital Bed; Mental Health. 
O tema da sexualidade, há muito tempo, vem ocupando as discussões de teóricos de várias áreas de conhecimento. Uns vão na direção de reconhecer a grande variedade de gênero e formas de exercer a sexualidade e outros vão ao sentido oposto, tentando classificar e patologizar essa variedade (ÁVILA, 2014). Segundo Arán (2006), é a partir do século XVII que as teorias biológicas da sexualidade e as condições jurídicas impostas aos indivíduos foram conduzindo à refutação da ideia da presença e mistura de dois sexos em um só corpo, sendo que a homossexualidade já era considerada como uma condição desviante e anormal.

Notamos, nos discursos que nos cercam, que a transexualidade é tratada como uma contradição entre corpo e subjetividade ou, dito de outra forma, uma incoerência entre sexo e gênero (ARÁN, 2006). Sexo, nessa perspectiva, é algo definido pela natureza, pelo corpo orgânico, biológico e genético, um dado a-histórico. Contrapondo o sexo, o gênero é algo que se adquire por meio da cultura, construído histórica e socialmente (Idem).

No contexto atual de redefinições de olhares e perspectivas com a população que expressa sua identidade e sexualidade de diversas formas, sejam elas contradizendo ou não seu sexo de nascimento, surgem os movimentos de Lésbicas, Gays, Bissexuais, Transexuais e Travestis (LGBT). Esses movimentos deslocam-se da discussão patologia/identidade para lutar por igualdade de direitos em espaços sociais e jurídicos.

Podemos pontuar dois avanços significativos em termos de legislação em favor da população LGBT. O primeiro foi a criação da Portaria $\mathrm{n}^{\circ} 2.836$, de $1^{\circ}$ de dezembro de 2011, a qual instituiu, no âmbito do SUS, a Política Nacional de Saúde Integral LGBT. Esta política visa, dentre outras coisas, o atendimento e acesso igualitário aos serviços de saúde, pautados no respeito à identificação de gênero que o usuário possui. Após, a Portaria ${ }^{\circ} 2.803$, de 19 de novembro de 2013, que redefine a amplia o Processo Transexualizador no SUS.

Para Arán, Murta e Lionço (2009), a gestão participativa e o protagonismo do movimento social "são fundamentais para que ações em saúde venham a responder e espelhar as reais necessidades e os valores específicos de diferentes grupos sociais, consumando a proposição de modelos de atenção justos rumo à equidade" (ARÁN; MURTA; LIONÇO, 2009, p. 46-47).

A $1^{\text {a }}$ Conferência Nacional GLBT ${ }^{1}$ (BRASIL, 2008) pede alguns encaminhamentos que vão nesse sentido. Um exemplo é o pedido de implantar e implementar, nos serviços de saúde, o uso do nome social nos prontuários de atendimento. Arán, Murta e Lionço (2009) concordam que esta é uma estratégia de promoção de acesso aos serviços, beneficiando diretamente transexuais e travestis por meio do acolhimento que será prestado.

A própria conferência supracitada indica, em dois tópicos relativos à saúde, a necessidade de discussões a respeito da sexualidade e de gênero nas equipes de saúde. Um dos tópicos fala em desenvolver, implantar e implementar ações e práticas de Educação em Saúde nos serviços do SUS com as temáticas de

1 Esta nomenclatura vem sendo modificada ao longo do tempo, atualmente a sigla utilizada é LGBT. 
orientação sexual, gênero, entre outras. E a outra concerne ao atendimento em saúde mental, em que o tópico afirma a necessidade de qualificar esta atenção em todas as fases de vida da população LGBT, prevenindo agravos decorrentes dos efeitos do preconceito e da discriminação, e garantindo uma política de redução de danos do abuso de álcool e outras drogas e da exclusão social (BRASIL, 2008).

Nesta conjuntura, propusemos uma pesquisa para conhecer os aspectos relacionados às decisões por parte de equipes de saúde mental em serviços que possuem leitos de permanência noturna, denominados "masculinos" e "femininos". A $1{ }^{\text {a }}$ Conferência Nacional GLBT apresenta dois tópicos em que se fala de momentos de internação de travestis e transexuais. O tópico 81 pede a garantia da internação na ala feminina para travestis e transexuais femininas em toda a rede de saúde, e o tópico 96 pede a garantia à população LGBT o direito de escolha, no caso de internação hospitalar, entre as alas feminina e masculina (BRASIL, 2008).

Até o momento, não foram encontrados dados referentes à permanência em leitos masculinos ou femininos de serviços de atenção especializada de saúde mental, como são os CAPS III e as internações psiquiátricas. Algumas pesquisas foram encontradas com relação à internação hospitalar de usuários travestis e transexuais para cirurgias de redesignação sexual. Com elas, chegamos à conclusão que, nas internações que visam à cirurgia de transgenitalização, há respeito ao sexo identificado pelo usuário (ARÁN; MURTA, 2009). Em internações decorrentes de situações clínicas no SUS, em geral, não há escolha e o usuário acaba internando em um leito conforme seu sexo de nascimento (MULLER; KNAUTH, 2008; CIRILO; MIRANDA, 2012).

\section{Objetivos}

Dito isto, o objetivo deste artigo é apresentar, através de narrativas, o que as equipes de uma internação psiquiátrica de uma rede hospitalar e de um CAPS AD III, ambos do Rio Grande do Sul, têm a dizer sobre o tema, buscando pontuar semelhanças e diferenças em seus discursos. Esta pesquisa se constitui do trabalho de conclusão de residência da autora principal, que teve como título 'A binária heterossexual e os serviços de saúde'.

\section{Metodologia}

Este estudo se caracterizou como qualitativo e de abordagem exploratória. A pesquisadora realizou uma de coleta de dados que envolveu a criação de um caso hipotético construído com base em histórias reais retiradas de blogs de mulheres trans e perguntas norteadoras de discussão. $O$ caso hipotético problematizava a questão do uso de álcool e outras drogas e o sofrimento psíquico na relação com a transexualidade, sendo que a personagem trans necessitava de permanência 24 horas em um CAPS AD ou internação psiquiátrica. $\mathrm{O}$ caso e as perguntas foram discutidos em um grupo focal com cada equipe, os quais tiveram duração de mais ou menos 1 hora cada e contaram com a participação de 11 profissionais na internação psiquiátrica e 
10 no CAPS AD III.

As falas dos grupos foram gravadas, transcritas e posteriormente transformadas em narrativas, por meio da extração de seus núcleos argumentais, conforme método proposto por Onocko-Campos e Furtado (2008). Um segundo momento foi realizado após a sistematização em narrativas, com um novo grupo focal para apresentar e discutir a pré-análise com os envolvidos. Dessa forma, a construção da narrativa final foi feita de forma conjunta entre pesquisador e equipe participante.

Nesta pesquisa, a análise foi realizada segundo o Método Narrativo citado. Trata-se da 'vinda ao mundo de um texto', ou seja, a narrativa enquanto mediadora entre experiência e discurso, ação e linguagem, indivíduo e sociedade, e estrutura e acontecimento. Segundo os autores, esse método aplicado a Grupos Focais em saúde mental permite explorar as relações entre estrutura e eventos observados e/ou registrados nos serviços de saúde, fugindo da dicotomia entre macro e micropolítica nas pesquisas, dando densidade a múltiplas vozes inseridas no contexto.

\section{Resultados e Discussão}

Após a realização do processo descrito acima, extraímos oito temas em comum das falas das equipes. São eles: 1. Decisão sobre o leito; 2. Entendimento de transexualidade; 3.Como é/imaginam o processo de trabalho com trans? Outras questões do tratamento/atendimento; 4. Experiências no CAPS; 5. Experiências nos serviços e na vida; 6. Conhecimento de leis ou portarias sobre a questão LGBT ou cursos; 7. Pré-conceitos (núcleo do CAPS AD III)/Preconceito, estranhamento, cultura, visibilidade (núcleo da Internação psiquiátrica); 8. Dúvidas e outros comentários sobre o tema. A seguir, apresentaremos as narrativas das equipes para cada tema explorado nos grupos focais.

\section{Decisão sobre o leito}

Ao discutir sobre 'em qual leito' (se feminino ou masculino) a pessoa do caso hipotético ocuparia nos serviços de saúde mental, um aspecto foi comum nos dois grupos focais: a escuta e consideração da opinião dos outros pacientes internados ou em permanência 24 horas.

A equipe da internação considerou importante avaliar como seria a aceitação dos outros pacientes internados, pois a equipe teme que poderia acontecer situações de violência contra a paciente, como piadas de cunho negativo ou assédio sexual. Concordaram que essas situações poderiam agravar ou criar um quadro depressivo na paciente. A equipe percebeu, então, que uma intervenção com os pacientes é necessária nesses casos, seja em forma de uma conversa ou de discussão sobre a situação da pessoa internada, explicando sua condição de internação em um quarto feminino. Isso foi pensado para diminuir ou cessar o estranhamento dos outros pacientes, não para expor a pessoa.

No CAPS AD, apesar de outras problematizações, todos concordaram que se ela se considera mulher, ela é uma mulher. Nesse sentido, essa parece ser 
uma questão de autodeterminação, assim como é a questão de raça e cor. Levando isso em consideração, a paciente do caso hipotético deveria ir para o quarto feminino. Alguns membros da equipe entendem que, hoje em dia, é mais tranquilo lidar com questões como essa, mas, que mesmo assim deve ser conversado com as outras mulheres que estão no quarto. Evita-se, com a consulta aos pacientes, um autoritarismo e um moralismo da equipe na resolução dessa questão.

A inclusão da percepção dos outros pacientes em permanência no CAPS também se justificou devido a alguns profissionais pensaram haver "um homem por baixo das roupas" da transexual. Ideia essa que não foi aceita por outros membros da equipe, pois "qual ameaça um pênis em uma pessoa que se identifica como mulher traz pras outras mulheres?" (questionamento de um membro da equipe). Nesse sentido, pontuou-se que a justificativa está nas possíveis violências que essa pessoa poderia sofrer em um local em que não é aceita. É possível que se esteja expondo a paciente ao risco de sofrer violência quando a equipe não ouve o que os outros estão dizendo, e estar em risco dentro de um espaço protegido é um agravante. Para solucionar esse problema de não aceitação, equipe e paciente teriam que pensar em um plano B juntos, reconhecendo que o CAPS passa por momentos diferentes e as decisões podem variar conforme esses momentos.

A equipe da internação ainda levanta a questão dos familiares dos pacientes, tanto os da pessoa trans, que podem não aceitar sua condição, como para os outros pacientes internados. A equipe imaginou que eles possam contestar a internação da pessoa em um leito feminino. Pensaram hipoteticamente em um paciente dizendo para a família que a outra paciente é homem, e isso despertaria um questionamento do familiar a respeito do motivo disso. Nesse sentido, trabalhar o tema da transexualidade no grupo de familiares da internação pareceu uma alternativa viável, segundo a equipe.

Ambas as equipes pontuaram a importância de pensar sobre esse tema. A da internação concordou que a hospitalização é um momento de fragilidade para qualquer pessoa e que, sendo somado a isso um possível conflito a respeito de qual leito ir, a fragilidade pode se acentuar; discutir em equipe faz-se necessário para não aumentar sofrimento à paciente. Já a equipe do CAPS AD reiterou a importância em incluir a temática LGBT nos espaços de discussão que os pacientes têm, visando estimular a reflexão, pois decidir sobre algo sem discutir "seria alimentar o preconceito e a exclusão". A equipe entende que a discussão é importante mesmo no caso da pessoa não ficar no quarto, pois fora dali todos conviverão com ela no dia a dia e precisam respeitá-la.

As autoras Arán, Murta e Lionço (2009) concordam que todos os atores envolvidos num processo decisório como esse devem ser ouvidos e considerados. Elas afirmam que a gestão participativa e o protagonismo do movimento social são considerados fundamentais para que as ações em saúde sejam congruentes com as reais necessidades e com os valores dos diferentes grupos sociais. Ao fazer uma gestão como esta, que considere todos os atores envolvidos, está se consumando a proposição de modelos de atenção rumo à equidade, e que constroem um SUS mais humanizado. Além disso, está se considerando como cidadãos empoderados pacientes e familiares que historicamente permaneceram em situação passiva nas propostas de plano 
terapêutico indicadas pelos profissionais de saúde.

Outro assunto em comum entre as equipes foi com relação à reserva de um leito ou um quarto específico para pessoas trans. Em tom de brincadeira, uma pessoa da equipe da internação sugeriu que o quarto com dois leitos, que podem ser tanto femininos quanto masculinos, ficasse só para casos de transexualidade, mas essa ideia foi recusada por todos sem que fossem ditos argumentos justificando a contrariedade a isso.

No CAPS AD essa foi a primeira tentativa de solução sobre o caso hipotético dado e partiu de um integrante da equipe que pensou que, havendo um quarto inteiro disponível, este terceiro quarto poderia ser usado para a paciente. Essa ideia foi questionada pelo resto da equipe, pois entendem que botá-la num quarto separado seria segregá-la pela sua diferença. Até brincou-se que, se fosse efetivado esse quarto separado, teriam que ser criados quartos para quem possui aspecto de homem, para quem possui aspecto de mulher, para quem fez a cirurgia. Assim teriam quartos pra todas as possibilidades de diferenças.

A equipe demonstrou preocupação ao imaginar uma mulher trans querendo ficar em um quarto masculino e isso sendo problema para os outros pacientes. Propõe uma conversa com os homens sobre suas percepções e como se sentiriam nessa situação. Caso houvesse uma negativa deles para a pessoa ficar nesse quarto e as mulheres também se recusassem a recebê-la, ou, ainda, se só existisse leito no quarto masculino, surge o terceiro quarto ou a sala de observação como solução pra essa situação.

A questão sobre internação ou permanência em leitos/quartos no caso de pessoas trans e travestis foi pesquisada em 2012 por Cirilo e Miranda em serviços secundários e terciários da capital paulista. A pesquisa deu-se através de um questionário que solicitava informações acerca da estrutura oferecida nos casos de internação, como a localização dos leitos e uso do banheiro, além do tratamento nominal.

Nesta pesquisa, dos 39 ofícios enviados, 37 locais afirmaram usar o nome social. Quanto à identidade de gênero na distribuição de leitos e uso de banheiros durante a internação hospitalar, apenas quatro hospitais manifestaram respeito a ela. Os autores apontaram que também são consideradas as necessidades dos pacientes em relação ao diagnóstico e prognóstico e à disponibilidade de vagas para a internação. Estes são apontamentos também levantados pela equipe do CAPS AD.

Os autores da pesquisa ainda apresentam outras respostas ao questionário que referem desconsideração à identidade de gênero, ou superficiais e evasivas dos outros 35 locais (CIRILO; MIRANDA, 2012). Com isso, vemos o quanto ainda é incipiente o pensar no atendimento às especificidades dessa população com base na Política Nacional de Saúde Integral LGBT.

Outros pontos surgiram nas discussões e que não foram compartilhadas pelas diferentes equipes, por exemplo, a questão dos documentos que surgiu na narrativa da equipe da internação. Estar com documentos masculinos é um impeditivo para internar num leito feminino, exceto se há uma comprovação jurídica de que a pessoa é mulher apesar disto - caso verídico ocorrido em outro setor do hospital. A equipe também lembrou que os leitos vagos são gerenciados pela central do hospital e, antes disso, pela central de regulação do 
município, que registraria o leito segundo os documentos apresentados. Apesar do registro ficar masculino, a equipe iria se referir a ela da forma como ela preferisse ser chamada.

Por questão de lógica, a equipe não pensou que uma paciente como a do caso hipotético ficaria em um quarto masculino, pois deve-se levar em consideração a autodenominação de mulher. Alguns integrantes da equipe pontuam que a permanência nesse leito depende de ela manter o respeito no local, no sentido de ser tolerante com o estranhamento que despertará nos outros pacientes.

A equipe também concordou que seria necessário fazer um acionamento da gerência de internação e até da direção do hospital para que houvesse uma mudança. Isso seria necessário, pois, a equipe acredita que situações semelhantes a do caso hipotético apresentado se tornarão mais frequentes.

A questão do nome social é apontada na literatura como sendo uma das principais estratégias de promoção de acesso aos serviços pelas transexuais e travestis, pois a falta de acolhimento adequado é considerado um dos principais fatores da exclusão do SUS (ARÁN; MURTA; LIONÇO, 2009). Ávila (2014) também comenta sobre a importância que reside nos documentos que reconhecem a identidade das pessoas trans e dos serviços que respeitam isso. A autora afirma, porém, que esta estratégia de inclusão não resolve definitivamente os problemas enfrentados no cotidiano de quem continua a apresentar o nome de registro em documentos oficiais.

A partir disso, podemos pensar, além das pessoas que ainda apresentam seus documentos anteriores à mudança de nome, também nas instituições que reconhecem a identidade apenas por esses registros, como no caso citado no grupo focal da internação. Essas instituições dificultam ou precarizam o acesso aos seus serviços, além de deixar de levar em consideração a Carta dos Direitos e Deveres dos usuários da saúde (MINISTÉRIO DA SAÚDE, 2009), que prevê que as pessoas sejam reconhecidas pelo seu nome social. Frente a essa problemática, a equipe da internação interviria junto aos órgãos reguladores da unidade para que houvesse uma mudança, o que seria uma solução para os casos futuros que chegarem à unidade.

Finalizando este tema, a equipe do CAPS AD entendeu que deve levar em consideração as vagas nos leitos do serviço, a escuta do desejo da paciente e depois discutir o caso em equipe e com os outros pacientes. Mesmo assim, um integrante da equipe acredita que a opinião da pessoa deve ser a mais valorizada na escolha do leito. A equipe da internação compartilha desta visão de escuta da paciente e de considerar mais adequado um quarto feminino para o caso que se apresenta. Esse processo relatado pelas equipes está em conformidade com a Política Nacional que reafirma a necessidade de ouvir e respeitar o desejo do usuário, mesmo que as equipes desconheçam tal política.

Lembramos que, anterior à Política Nacional de Saúde Integral LGBT, instituída em 2011, a Conferência Nacional GLBT de 2008 já pedia a garantia de internação na ala feminina para travestis e transexuais femininas em toda a rede de saúde, e que toda a população LGBT tenha garantido o direito de escolha, no caso de internação hospitalar, entre as alas feminina e masculina (BRASÍLIA, 2008).

Em 2009, Arán e Murta realizaram uma pesquisa na qual identificaram que,

Cristiane Camponogara Baratto, Eliana Dable de Mello, Lívia Zanchet 
A Transexualidade em Questão em Serviços de Saúde Mental com Leitos

Masculinos e Femininos no Rio Grande do Sul

em caso de internação médico-hospitalar de homens e mulheres transexuais em decorrência de sua transição sexual, na maioria das vezes, são internados na enfermaria em conformidade ao sexo com o qual se identificam socialmente, a despeito do nome que conste no registro civil, ou em um leito reservado para este programa assistencial. Ao contrário disso, em 2008, Muller e Knauth realizaram uma pesquisa com usuárias do SUS travestis que afirmaram ficar hospedadas em quartos masculinos, sem que fosse dada a possibilidade de irem para um quarto feminino ou com outras travestis. Sendo assim, elas são tratadas a partir do sexo biológico e vistas, como afirmam as autoras, "como homens vestidos de mulher" (MULLER; KNAUTH, 2008, p. 07).

Nessa lógica, finalizamos este tema de discussão valorizando a importância que as equipes deram à escuta e à inclusão dos outros atores envolvidos em um processo decisório como o proposto. Ávila (2014) afirma belamente que "o que diferencia um tratamento patologizante de um tratamento ético é a primazia da proteção do desejo que se oferece" (ÁVILA, 2014, p.106).

\section{Entendimento de Transexualidade}

Como primeiro entendimento de transexualidade, a equipe da internação construiu um comparativo com o 'homossexualismo' entendendo que são coisas diferentes. Para eles, o homossexual aceita o corpo da forma que é e tem a opção sexual pelo mesmo sexo, enquanto o transexual se identifica com o outro gênero, empreende mudanças físicas e prefere coisas do sexo oposto. Comentaram, a partir disso, sobre as nuances da questão, como o homossexual ter traços do sexo oposto sem necessariamente identificar-se com ele.

Guaranha (2014) empreende uma análise sobre a recorrência da associação da transexualidade e travestilidade com a homossexualidade pela maioria dos profissionais de saúde e que pode ser uma via de entendimento do que surgiu na discussão da equipe da internação. Segundo a autora, isso deve-se a uma concepção essencialista de sexo e gênero que leva a pensar que a população ' $\mathrm{T}$ ' é necessariamente homossexual, uma vez que são considerados homens, e os relacionamentos afetivos e sexuais com outros homens caracterizariam a homossexualidade (GUARANHA, 2014).

Nesse mesmo sentido, a equipe do CAPS AD faz uma comparação da transexualidade com o que um membro da equipe chamou de "espectro". Um paciente específico foi citado como exemplo de que era difícil saber se ele se identificava com homem, com mulher ou com os dois. Entenderam, em determinado momento, que esse paciente era travesti. Travesti, para a equipe, além de se travestir, é alguém que se identifica com ambos os sexos, masculino e feminino, e não vê problema em manter seu órgão sexual porque ele também é parte de sua identificação. Isso diferenciaria a travestilidade da transexualidade.

A transexual foi entendido como alguém que não se identifica com o gênero o qual nasceu, por exemplo, se nasceu masculino, se identifica com o feminino. Além disso, a transexual não se identifica com o próprio corpo. Nesse sentido, um membro da equipe define que a transexual é a pessoa que nasceu com o corpo errado e assumiu o estereótipo daquele gênero com o qual se identifica, independente de ter realizado cirurgia ou não. Conforme um 
curso que alguns fizeram, transexual é a pessoa que não se identifica com o sexo biológico que ela nasceu, tanto homem quanto mulher.

$\mathrm{Na}$ literatura, encontramos diversas discussões e tentativas de conceituação de transexualidade e travestilidade, alguns levando em conta aspectos biológicos, outros culturais, outros indo pela via da teoria queer ${ }^{2}$ e outros considerando como dimensão patológica. Neste trabalho, entendemos as pessoas trans como aquelas que:

possuem ou vivem/representam uma identidade de gênero diferente da atribuída ao nascer, incluindo aquelas que por obrigação, preferência ou livre escolha optam por apresentar-se, através da vestimenta, acessórios, cosméticos ou modificações corporais de modo diferente das expectativas a respeito do papel de gênero atribuído ao nascer (ÁVILA, 2014 apud BLAZER, 2010, p. 81).

Com relação à travestilidade, que surgiu nas discussões desta equipe, podemos afirmar que a maioria das travestis não busca o reconhecimento de uma identidade exclusivamente feminina ou masculina - como vemos na fala sobre o paciente que parecia se identificar com os dois gêneros -, e nem referenciam a realização da cirurgia como forma de corporificação de sua experiência (GUARANHA, 2014). Esta autora ainda afirma que, de uma maneira geral e simplista, os trabalhadores da saúde têm um olhar sobre as mulheres trans que as consideram como "uma alma feminina presa em um corpo masculino", enquanto a travesti é considerada como um "homem que se veste e se porta como mulher", discursos semelhantes aos que surgiram na narrativa da equipe do CAPS AD para tentar diferenciar as sexualidades do "espectro".

Os traços da transexualidade, para a equipe da internação, às vezes se apresentam de forma exagerada, o que pode ser lido por alguns como uma tentativa de superação da transexual sobre as mulheres. Outro membro da equipe manifestou a crença de que por trás dessa aparência, existe um grande sofrimento, pois ela sabe que "não é mulher". Essa afirmação foi baseada em uma colocação sobre a impossibilidade de gestação. Denotando o sofrimento apontado, no livro de Ávila (2014), isso é discutido em vários momentos com relatos dos participantes de sua pesquisa, como "eu sou pela metade, sempre vou fazer parte de dois mundos" (ÁVILA, 2014, p.121). Então, além do não ou do parcial reconhecimento de sua identidade no meio social, a própria consideração das questões biológicas que permanecem inscritas no corpo são causa de sofrimento.

Apesar disso, a equipe entende a importância da transformação física para a autoestima/autoafirmação da pessoa, que passa a conseguir se olhar e se gostar. Essa transformação também foi vista como importante para o reconhecimento social dela, como alguns casos famosos na mídia. A equipe também apontou casos de transexuais que optam por não fazer a cirurgia, sendo importante ter caracterização feminina por meio de adornos.

2 Afirma que a orientação e a identidade sexual ou de gênero são construídas socialmente, permitindo várias formas de desempenhar um ou vários papéis sexuais. 
Chama-se de Montagem esse "processo de manipulação e construção de uma apresentação que seja suficientemente convincente, sob o ponto de vista das travestis e transexuais [grifo nosso], de sua qualidade feminina" (ÁVILA, 2014, apud BENEDETTI, 2000, p.60). Essa exibição de caracteres femininos e o reconhecimento disso - mesmo que pareça exagero aos olhos dos outros mostra a centralidade que tem para as identidades trans a transformação e adornamento do corpo, e isso é retificado por essas pessoas (ÁVILA, 2014).

Outra questão que surgiu nas discussões do CAPS AD foi com relação à pessoa ter realizado ou não a cirurgia de redesignação sexual, no sentido de tentar identificar se isto muda ou não a forma de chamar a pessoa. Segundo um membro da equipe, por baixo da roupa existirá um homem quando a cirurgia não é realizada. Muitos acham que "transexual" e "transgênero" são dois conceitos parecidos e até podem ser a mesma coisa se partir do entendimento de que a cirurgia não afeta a nomenclatura. $\mathrm{O}$ que muda, como um membro da equipe apontou, é a identificação da pessoa que passaria a apresentar-se como "trans operada".

Com relação à noção de transgênero, o DSM-V define como "um amplo espectro de indivíduos que, de forma transitória ou persistente, se identificam com um gênero diferente do de nascimento" (DSM-V, 2014, p. 451). Guaranha (2014) afirma que esta noção é utilizada por um grupo minoritário e quer dizer o borramento das fronteiras de gênero. Este termo, porém, é pouco utilizado nas produções acadêmicas brasileiras e pouco utilizado pelas pessoas do/no campo (GUARANHA, 2014).

A equipe do CAPS AD comentou sobre a definição de sexo/gênero da pessoa depender do ponto de vista que se pensa a questão. Por exemplo, do ponto de vista biológico, é a presença de vagina ou pênis que define a pessoa. Do ponto de vista cultural, não se torna uma resposta tão simples, mas a equipe não aprofundou essa discussão.

Com relação às definições de sexo e gênero, Áran (2006) afirma que em geral, parte-se do pressuposto de que sexo (homem ou mulher) é definido pela natureza, é corpo orgânico, biológico e genético a-histórico e de que gênero é adquirido cultural, histórico e socialmente. Segundo a autora, essa tese determinista e ao mesmo tempo construtivista, restringe a possibilidade de compreensão das subjetividades e das sexualidades existentes. $\mathrm{O}$ gênero, se entendido dessa forma, parece uma construção imposta sobre um corpo-sexomatéria antes determinado, mas na verdade, "é um efeito performático que possibilita a constituição e o reconhecimento de uma trajetória sexuada, a qual adquire estabilidade em função da repetição e da reiteração de normas" (ARÁN, 2006, p. 51).

Já na internação, um membro da equipe realizou uma pesquisa prévia ao grupo focal e referiu ter encontrado a transexualidade ligada à dimensão de transtorno. Com essa colocação, a equipe lembrou com tom de ironia uma proposta de lei que sugeriu tratamento para a população homossexual (PDC 234/2011). Constatam a dimensão do sofrimento da pessoa e pensam que uma lei como esta pode fazer com que a transexualidade se torne um transtorno, mas que pelo simples fato de se identificar com o outro sexo não caracterizaria um transtorno mental.

É importante explorar essa dimensão de transtorno que aparece nessa fala 
sobre a transexualidade. Até o DSM IV-TR, havia um capítulo destinado ao diagnóstico "Transtorno de Identidade de Gênero", onde ali estavam a transexualidade, travestilidade, entre outros. Na versão mais recente, o DSM-V (2014) muda este capítulo para "Disforia de gênero" e explica que esse termo é mais descritivo e foca a disforia, entendida como sofrimento causado pelo descontentamento com o gênero designado, como um problema clínico, e não como a classificação de uma identidade.

No DSM-V ainda encontramos definições de sexo como indicadores biológicos de masculino e feminino, conforme a capacidade reprodutiva, gênero como papel público desempenhado, transgênero como espectro (termo usado por um membro da equipe em determinado momento) de indivíduos que se identificam com um gênero diferente do de nascimento, e transexual como quem busca/passa por uma transição social e/ou somática para outro gênero que não o atribuído ao nascer.

Esse tema de discussão gerou muitas dúvidas que, por vezes, fizeram a equipe da internação se questionar a respeito da transexualidade dar-se a partir do nascimento em um corpo errado, ou se é algo construído desde a infância e percebido através de traços, ou se é uma escolha da pessoa. Não se chegou a uma só definição ou entendimento de transexualidade. A dimensão da escolha também entrou em questão para a equipe do CAPS AD. Uma pessoa expressou que ser transexual não se trata de escolha, mas sim de identificação com a condição que a pessoa sente que é. Outro comparou com a heterossexualidade afirmando que a pessoa não escolhe gostar do sexo oposto, não é uma decisão que ela toma, até porque acredita que ninguém escolheria o lado mais difícil e de maior sofrimento.

Algo muito interessante que aconteceu durante todo o grupo focal realizado com a equipe do CAPS AD foi que os participantes pontuaram uns aos outros quando havia a troca de pronome "ela" por "ele" e quando se falava em ser "totalmente" ou "praticamente" mulher, no intuito de afirmar que são mulheres a partir do momento que se consideram como uma. Essa troca e confusão de pronomes também ocorreu na internação, mas sem que houvesse uma discussão sobre isso ou intervenções entre os participantes do grupo.

\section{Como é/imaginam o Processo de Trabalho com Trans? Outras Questões do Tratamento/Atendimento}

Neste tema, a equipe da internação demarcou que teve dificuldade em falar ou pensar possibilidades de resposta, pois parece uma realidade ainda distante da unidade. Mesmo assim, um ponto que foi comum nas duas discussões das equipes foi com relação aos banheiros. A equipe da internação mostrou preocupação com o uso dos banheiros da unidade, mas logo viram que eles não seriam problemas, pois os banheiros já são usados conforme a proximidade e não pelo gênero definido na placa de entrada. Um membro da equipe chegou a sugerir a retirada das placas naquele mesmo momento.

A equipe do CAPS AD também mencionou o fato dos banheiros serem separados em masculino e feminino e não serem banheiros mistos ou vestiários - assim como não se têm quartos mistos. O restante da equipe não viu os banheiros como problema, afinal são individuais e não são de uso coletivo, não 
causando constrangimentos. Ambas as equipes pensaram esse ponto exclusivamente dentro de seu local de trabalho como não sendo gerador de preconceitos e discriminação. Mas, segundo alguns autores essa é uma questão importante para as pessoas trans, pois além de ser um fator de exclusão desde a infância no contexto escolar, isso é gerador de violências e preconceitos ao longo da vida e em outros contextos (ÁVILA, 2014; CIRILO; MIRANDA, 2012).

Segundo uma pesquisa realizada com hospitais públicos de São Paulo, a oferta de banheiros unissex está presente em três hospitais dentre os trinta e nove que responderam o questionário enviado (CIRILO; MIRANDA, 2012). Podemos pensar que a realidade dos hospitais brasileiros ainda é a de divisão de banheiros segundo a lógica binária homem-mulher, mesmo que em alguns casos o uso dos banheiros seja flexível, como acontece na internação psiquiátrica aqui referida.

A equipe da internação reconheceu que deve pensar em como cada profissional vivenciará a transexualidade na sua unidade de trabalho, pois muitas vezes o preconceito existe na pessoa sem mesmo ela saber a dimensão de estranheza que sentirá. Nesse sentido, fazer esse movimento de falar e pensar a respeito dessas questões, ajuda o autoconhecimento e é visto pela equipe como uma forma de cuidado. Tanto a equipe da internação quanto a equipe do CAPS AD entenderam que suas condutas no tratamento da população trans, além da questão do leito, deve pautar-se no cuidado com os outros pacientes, no respeito, no cuidado do espaço de ambiência e no respeito a forma como a pessoa quer ser chamada. As equipes afirmam que acolheriam a paciente trans da mesma forma que faz com qualquer outra pessoa, sem diferenciação, mesmo que "algumas situações possam acionar uma contratransferência, no sentido de um rechaço contra a paciente" (narrativa da internação). Essa fala não foi discutida, mas vemos a dimensão de cuidado e respeito que permeiam essas falas sobre o trabalho com a pessoa transexual em seus serviços.

A partir disso, podemos pensar que ações como a da pesquisa realizada nos dois serviços podem compor os processos de educação das equipes. Tanto a residência em saúde que é parte da Política Nacional de Educação Permanente em Saúde quanto uma pesquisa com caráter reflexivo sobre as práticas de trabalho podem ser o primeiro contato com o tema de gênero e sexualidade das equipes. A demanda para inserção das temáticas de orientação sexual, identidade de gênero, pessoas com deficiência, e étnico-racial nos processos de educação dos serviços do SUS estão presentes desde a $1^{\text {a }}$ Conferência Nacional GLBT (BRASÍLIA, 2008), mas, ainda hoje, a exemplo dos serviços pesquisados, pouco ou nada se discute sobre isso nas equipes. É necessário, então, ampliar o debate sobre esse tema entre os profissionais de saúde como uma forma de qualificar o atendimento a essa população (MULLER; KNAUTH, 2008).

A equipe da internação pontuou, ainda, as questões técnicas específicas do núcleo profissional da enfermagem, profissionais em maior número na unidade, como também não havendo diferenciação ou problemas no cuidado. Foi citada como exemplo a questão do banho, se um profissional homem ou mulher acompanharia a paciente transexual. Concordaram que o 
acompanhamento se daria da mesma forma como já acontece com os outros pacientes, salvo o caso em que o paciente não aceite a organização prévia.

A equipe do CAPS AD também citou uma particularidade de seu serviço que até o momento não havia sido percebida como geradora de conflitos: o Grupo de Homens e o Grupo de Mulheres. Esses grupos são definidos pelo técnico de referência do paciente sem critérios exatos para indicação, o que foi questionado pela própria equipe durante o grupo focal com alguns casos de exemplo de não identificação com o grupo indicado.

Ainda foi pontuado pela equipe da internação o quanto pode haver diferença na forma de acolhimento e tratamento entre os profissionais que estão no turno. Isso indica a sensibilidade que nem todos os trabalhadores demonstram sobre o tema da transexualidade e o quanto um processo decisório como o leito de internação é de pessoas isoladas quando não se tem conhecimento de uma política norteadora.

Alguns membros da equipe da internação também referiram trabalhar na unidade de internação de meninas adolescentes com necessidades de cuidado em decorrência do uso de álcool e outras drogas, o que faz com que o tema da transexualidade e homossexualidade na adolescência surja demarcando que pode haver uma diferença de manejo, mas sem que se aprofunde nisso. Isso reflete a incipiência da questão trans na infância e adolescência nas pesquisas acadêmicas e na mídia como um todo, até o momento.

\section{Experiências na Internação e no CAPS}

Ao ser questionada sobre as experiências de internação de transexuais na unidade, a equipe concordou que isto ainda não ocorreu. Lembrou que receberam um paciente que namorava uma transexual. Ela foi definida como sendo diferente do que normalmente veem, não era extravagante como de costume, mas sim tranquila e discreta. Fica claro que o que se imagina de uma transexual é próximo dos estereótipos divulgados nas grandes mídias, como apontado pela própria equipe. Quando isso se apresenta na vida real, fora das tentativas de tornar humorístico um personagem LGBT, há o choque e a surpresa.

Dito isso, podemos problematizar dois pontos. O primeiro ponto é relativo à importância das imagens no processo de autoidentificação trans, discutido por Ávila, 2014. A autora afirma que a exibição de características femininas acentuadas aponta para a importância que a transformação do corpo tem na constituição da identidade da pessoa trans. Além disso, a imagem da transformação do corpo que circula na mídia também teve papel importante para a introdução da questão trans e LGBT como um todo no senso comum (ÁVILA, 2014) e que acaba por ser reproduzido nos discursos dos profissionais de saúde.

$\mathrm{O}$ outro ponto que queremos dar destaque é que, às vezes, esconder seus adornos femininos e circular pelos espaços de forma discreta, sem chamar atenção para si é usado como estratégia pelas travestis ou mulheres trans para que consigam ser respeitadas nos espaços institucionais (GUARANHA, 2014). Aqui, a aparência não é vista como parte da identidade, mas como algo que deve permanecer no âmbito privado da vida para evitar situações de violência 
e preconceito.

Outra situação que às vezes acontece na unidade, segundo a equipe, diz respeito à peculiaridade da população atendida, como no caso de pacientes psicóticos que, dentro do seu delírio, reconhecem-se com outro gênero e com outro nome. Situações como essa causam confusão nos outros pacientes internados, mas a equipe entende que não se trata de uma questão de identidade, e sim de um estar psicótico a ponto de não saber quem é.

Já no CAPS AD, a equipe teve contato com alguns casos de pacientes trans. Primeiro foi relatado um caso de uma mulher considerada por todos como masculinizada e homossexual que ficou em um quarto feminino. Houve um constrangimento inicial das outras pacientes, o qual passou com o tempo. Alguns membros da equipe entendiam que ela poderia ter ficado no quarto masculino, já outros discordaram dessa possibilidade, pois não se trata de um caso de transexualidade.

Outro caso que discutiram foi o de uma paciente travesti que, em função da questão biológica, foi colocada no quarto masculino quando necessitou de permanência 24 horas. Essa paciente andava sempre com as mulheres do CAPS que a viam como mulher. A própria equipe, neste momento grupal, se questiona quanto à indicação do quarto masculino e concluiu que foi escolha do paciente "ser considerado como homem no espaço de tratamento".

Outro profissional relata que atendeu um caso de uma pessoa que havia iniciado o processo transexualizador no hospital de referência para isto no Rio Grande do Sul. Esse profissional achou difícil definir se era ele ou ela, pois o nome de registro era masculino, depois houve mudança para outro nome masculino e depois essa pessoa optou por parar o processo transexualizador, o que o deixou com uma aparência considerada "andrógena". Esse caso gerou estranhamento e risos na equipe, mas todos concordaram ser uma situação de bastante sofrimento pra pessoa por ela não identificar-se com nenhum ou com os dois sexos.

Estes três casos apareceram como desafio para a equipe, pois tem as fronteiras entre masculino e feminino borradas. Esta confusão, sentida pelo profissional da equipe do CAPS no terceiro caso, demonstra a tentativa de classificação que é pautada pela binária homem/mulher, masculino/feminino, que não permite a compreensão de uma coexistência de características que não têm nomeação. Este é um desafio a ser enfrentado, pois não existe um único processo de construção das identidades de gênero transexuais e, como afirma Arán, Murta e Lionço (2009), não devemos esperar deles/as um comportamento fixo, rígido e adequado às normas de masculino e feminino tradicionais.

Outro membro da equipe lembrou o único caso que atendeu de um homem transexual, transgênero ou travesti (houve dificuldade em definir o termo) que se vestia como mulher e tinha um nome social feminino. Apesar de não ter um campo pra isso na ficha naquele momento, foram colocados os dois nomes, o da certidão e o que o paciente queria ser chamado. Essa flexibilidade de adaptação do serviço conforme a demanda é essencial para que se reconheça o usuário como um cidadão de direitos independente de sua orientação sexual e sua identidade, mesmo que haja um desconhecimento da lei, como era o caso da profissional no momento.

Cristiane Camponogara Baratto, Eliana Dable de Mello, Lívia Zanchet 


\section{Experiências nos Serviços e na Vida}

A equipe da internação resgatou experiências em outros serviços e outras experiências que tiveram contato durante a vida que envolviam a transexualidade. Um membro da equipe relatou um caso que acompanhou, em seu trabalho anterior, em que uma pessoa foi pra uma fazenda terapêutica masculina, para tratamento de questões referentes ao álcool e outras drogas, que não aceitava transexuais. Essa pessoa teve que cortar os cabelos e se vestir de homem para ter tratamento. A equipe entendeu isso como uma violência contra a pessoa, e inferiram que a fazenda também parecia querer tratar a transexualidade dela.

Além disso, a equipe acredita que é visualmente impactante uma pessoa com características masculinas e femininas coexistindo, e isso é parte da criação preconceituosa que ainda temos nos dias de hoje que faz com que, por mais que não percebamos, podemos carregar uma marca de preconceito internamente. Descobrir esse preconceito nos causa surpresa, como num caso relatado por um dos membros da equipe. "É como se existisse uma lei que marca a diferença e não se pode fazer nada com isso" (fala de um membro da equipe).

A equipe do CAPS AD também compartilhou situações que viveram em outros trabalhos e em suas vidas pessoais, como um caso contado por um membro da equipe que em seu outro trabalho tinha uma paciente transexual. $\mathrm{Na}$ identidade ela ainda tinha o nome masculino, mas pedia a todos que a chamassem pelo nome feminino, para evitar constrangimentos. Quando um funcionário do local recusou-se a chamá-la pelo nome feminino, ela ajuizou um processo contra o local.

O chamar pelo nome pelos profissionais de saúde, que são considerados por Guaranha (2014) como a materialização do Estado, reconhece e legitima as identidades e existência desses sujeitos. Quando há uma recusa em chamar pelo nome, coloca-se em questão aquela vida; nas palavras da autora, "recusarse a reconhecer o gênero das travestis - e podemos incluir aqui também o das pessoas transexuais - é um meio de rejeitar seu próprio direito de existir" (GUARANHA, 2014, p. 83). É assim que são gerados inúmeros e frequentes constrangimentos nos usuários dos serviços de saúde que são chamados pelo nome de registro, tornando-se uma barreira no acesso ao atendimento (ÁVILA, 2014).

Outras situações foram citadas por essa equipe, como casos de homossexualidade que foram acontecer no avançado da vida de amigos. A equipe acredita que a sociedade está melhorando no sentido de melhor aceitação da pessoa pelo que a faz feliz.

\section{Conhecimento de Leis ou Portarias sobre a Questão LGBT}

A equipe da internação referiu não se lembrar de leis ou portarias que regem sobre a questão LGBT, apesar de reconhecer que existem. Foram citados algumas ações importantes de acolhida à pessoa como cidadã, por exemplo, a garantia de tratamento, a permissão para o casamento gay/homossexual, a permissão da realização da cirurgia pelo SUS e a mudança do nome. 
Já no CAPS AD, dois profissionais da equipe fizeram um curso a distância sobre a saúde da população LGBT há 2 anos. Neste curso, as nomenclaturas foram discutidas e uma ação no serviço foi feita. Foi dessa forma que se incluiu o nome social na ficha de avaliação/acolhimento do serviço que ainda não havia sido inclusa. A inclusão do campo "nome social" ocorreu oficialmente na ficha há apenas dois anos e com base em uma ação pedida em um curso que dois profissionais realizaram. No entanto, a Portaria $\mathrm{n}^{\mathrm{o}} 1.820 \mathrm{de}$ 2009, que afirma a necessidade dos serviços de saúde respeitarem a questão, já existia há 4 anos sem que a equipe a conhecesse.

É a partir disso que Guaranha (2014) afirma que, enquanto esta ação tiver baixa institucionalidade, não penetrar nos diferentes âmbitos do SUS, e não dialogar com os demais setores das políticas públicas, essa população não terá resposta plena aos seus anseios quanto ao uso do nome social.

Além disso, outro membro da equipe lembrou que no Rio Grande do Sul existe uma determinação a respeito da carteira com o nome social que pode ser usada como documento de identidade. Isso despertou interesse no restante da equipe que foi motivada a saber mais sobre isso. O uso do cartão que contém o nome social é uma estratégia para facilitar e qualificar o acesso de pessoas travestis e transexuais aos serviços de saúde (ARÁN; MURTA; LIONÇO, 2009), mas Ávila (2014) nos lembra que essa estratégia não resolve definitivamente os problemas enfrentados no dia a dia de quem não possui esse documento e segue apresentando o único nome recebido, o nome de registro.

Em ambas as equipes, diante da negativa de conhecimento de outras leis ou portarias vigentes sobre a questão da transexualidade que estão ligadas a questões de saúde, a pesquisadora instrumentalizou as equipes apresentando o cartão cidadão, a Política Nacional de Saúde Integral LGBT e as resoluções do Conselho Federal de Medicina sobre o processo transexualizador.

\section{Pré-conceitos (CAPS AD III) e Preconceito, Estranhamento, Cultura, Visibilidade (Internação Psiquiátrica)}

Ao discutir sobre a transexualidade, a equipe da internação falou de questões pertinentes ao contexto da cultura brasileira e ao contexto específico da cultura gaúcha. A equipe referiu ver uma polaridade no Brasil, sendo o "lado masculino" mais preconceituoso com as questões LGBT do que o "lado feminino". E nesse mesmo sentido, o Rio Grande do Sul foi considerado um estado culturalmente mais machista, cheio do que um membro da equipe chamou de "bombachudos enrustidos". Lembraram, como exemplo disso, da situação do incêndio de um Centro de Tradições Gaúchas (CTG) para que ali não houvesse um casamento gay.

Durante as discussões no CAPS AD foi pontuado por um membro da equipe que o leque de oportunidades de relacionamento deve ser amplo e acredita que as pessoas devam conversar mais para deixar essa questão mais flexível, usando o exemplo das filhas que devem procurar o que as fazem felizes. Houve um questionamento sobre aceitar isso também se fosse com um filho homem, pois a equipe julga ser mais fácil aceitar uma mulher homossexual do que um homem nessa condição. Isso fez com que outras pessoas falassem seu posicionamento ou de seus maridos caso os filhos fossem homossexuais ou 
transexuais.

Esses apontamentos sobre o machismo presente na nossa cultura, seja gaúcha ou brasileira como um todo, vão ao encontro com a fala de uma usuária travesti que acredita que se elas se sentem mulheres, devem ser consideradas como tal e ficar em leitos de acordo com esta identificação. Ela diz, ainda, que ficando em leito masculino os homens têm preconceito (MULLER; KNAUTH, 2008). Podemos problematizar essa questão pensando no quanto esse machismo é 'velado' e não discutido nos serviços de saúde, que acabam por reproduzir a lógica de um sistema que dicotomiza sexo e gênero e não tem espaço para a escuta do seu usuário.

Além disso, a equipe da internação aponta para um aparente crescimento da população LGBT, se comparado há 10 anos. Na fala de um membro da equipe, "É como se agora a população pudesse aparecer, ser visível", pois já não estão mais restritos às suas casas e podem aparecer nas ruas. Essa questão da visibilidade é citada por alguns autores (CIRILO; MIRANDA, 2012; ÁVILA, 2014; GUARANHA, 2014) como sendo crescente desde 1997, com a primeira resolução do Conselho Federal de Medicina sobre o processo transexualizador. Desde então, a população LGBT vem ocupando espaços na mídia nacional com notícias que vão de conquistas de direitos à violação destes, como repetidos casos de agressões físicas ocorridos em todo o Brasil.

Não podemos deixar de destacar que, na mídia televisiva, através de novelas e programas de humor, existem personagens com figuras esteriotipadas de travestis, transexuais e homossexuais que transformam esta condição em piadas que passam como naturalizadas aos olhos dos espectadores. A própria equipe da internação reconhece a existência e persistência de piadas sobre homossexuais, mesmo havendo uma aparente maior aceitação da população LGBT. Apesar disso, em determinado momento, um membro da equipe faz uma dessas piadas referindo-se ao aumento da visibilidade dessa população, como se a heterossexual fosse ser minoria em um futuro próximo. Isso nos mostra o quanto, por mais que se discuta sobre o tema da banalização do preconceito, ele está colado ao discurso dos próprios profissionais de saúde.

A equipe da internação também destaca brevemente o papel da escola no processo de aceitação ou exclusão de crianças com traços de outro gênero, mas não debateu sobre esse ponto levantado. Quanto ao papel da escola, as dificuldades e barreiras que pessoas trans e travestis que frequentam este ambiente passam, vêm sendo discutidas há algum tempo na literatura. Pesquisadores e militantes apontam que, além de existir preconceito e discriminação nesse espaço, isso se torna motivo para o afastamento de muitas dessas pessoas das instituições educacionais (GUARANHA, 2014). É nesse sentido que Ávila (2014) traz um relato sobre o sofrimento atrelado ao uso do banheiro na escola que teve como consequência a saída do aluno. Ela escreve que um participante de sua pesquisa "Foi expulso de uma escola, pois se recusava a usar o banheiro feminino e no masculino apanhou e sofreu violência sexual. Não sabia em qual banheiro entrar" (ÁVILA, 2014, p. 118).

Ao final das discussões na equipe do CAPS AD, um membro da equipe questiona qual é o problema de se permitir a algumas experiências e desabafa "não existe problema real nisso, mas sim convenções sociais feitas para acabar 


\section{Dúvidas e Outros Comentários sobre o Tema}

A equipe da internação, em alguns momentos da discussão, teve questões, curiosidades e dúvidas. São exemplos de dúvida: como se dá a cirurgia de redesignação sexual e a curiosidade sobre registros de homens transexuais, que pouco se via noticiado. Também houve questionamentos sobre orientação sexual das pessoas transexuais, se são heterossexuais ou podem ser homossexuais também.

A equipe também identificou situações em que a redesignação sexual não se faz necessária para a pessoa, bastando a forma de se vestir para gerar satisfação pessoal. Para alguns, isso pode gerar uma aparência forçada, pois a pessoa passará a acrescentar muitos adornos femininos ao seu visual, distanciando-se da aparência das mulheres.

Durante o grupo focal no CAPS AD, as dúvidas sobre a temática LGBT circularam em torno da "cura gay" (PDC 234/2011); dúvidas sobre a diferença de termos usados como lésbica e 'machorra', bissexual e 'gilete'. A própria equipe desconstruiu esses termos diferenciando-os entre os politicamente corretos e os pejorativos.

Uma questão persistente ao longo de todo o grupo focal no CAPS AD foi quanto à mudança ou não da nomenclatura quando se faz a cirurgia e, também, se existe diferença entre os termos transexual e transgênero.

As dúvidas apresentadas pelas equipes que não foram discutidas no primeiro grupo focal foram contempladas em discussão em um segundo momento grupal destinado à devolutiva e discussão das narrativas produzidas no primeiro encontro.

\section{Considerações Finais}

Falar sobre transexualidade implica refletir sobre todas as concepções existentes sobre o que é sexualidade, obrigando-nos a desconstruir binarismos rígidos presentes nas categorias de gênero tradicionais. É certamente um desafio para o pesquisador que se propõe a estudar esse tema e se torna ainda mais desafiador quando se propõe a fazer equipes de saúde pensarem e discutirem esse tema.

Entendemos que se faz necessário ampliar (ou iniciar) um debate sobre 


\section{Masculinos e Femininos no Rio Grande do Sul}

gênero e diversidade sexual entre os profissionais de saúde, pois isso implica em qualificar e humanizar o atendimento a essa população. Em se tratando de saúde mental, esse assunto é ainda mais delicado, pois qualificar o acolhimento e tratamento em todas as fases de vida da população LGBT nos serviços de saúde mental previne agravos decorrentes dos efeitos da homo/lesbo/transfobia e garante que danos decorrentes dos efeitos da discriminação, do uso de álcool e outras drogas e da exclusão social possam ser olhados e ressignificados.

Consideramos importante, ainda, que trabalhos como este, que permitam a reflexão sobre o próprio processo de trabalho das equipes sejam contínuos e crescentes, fazendo com que, além de publicações acadêmicas, haja modificações no cotidiano de trabalho com a população trans. Como vimos na pesquisa, ainda é tímida a procura dessa população pelos serviços de saúde, e isso se deve à historicidade de recorrentes atos de discriminação e preconceitos em espaços de cuidado, como os de saúde e saúde mental. Mudar o olhar sobre essa população é urgente para que essa realidade se transforme.

\section{Referências}

ASSOCIAÇÃO PSIQUIÁTRICA AMERICANA. DSM-IV. Manual Diagnóstico e Estatístico de Transtornos Mentais. Porto Alegre: Artmed, 2014.

ARÁN, Márcia. A transexualidade e a gramática normativa do sistema sexogênero. Ágora, Rio de Janeiro, v. IX, n. 1 jan/jun 2006.

ARÁN, Márcia; MURTA, Daniela, LIONÇO, Tatiana. Transexualidade e saúde pública no Brasil. Ciência \& Saúde Coletiva, v. 14, n. 4, p. 1141 - 1149, 2009.

ARÁN, Márcia; MURTA, Daniela. Relatório preliminar dos serviços que prestam assistência a transexuais na rede de saúde pública no brasil. Universidade do Estado do Rio de Janeiro: Rio de Janeiro, 2009.

ÁVILA, Simone. Transmasculindades: a emergência de novas identidades políticas e sociais. Rio de Janeiro: Editora Multifoco, 2014.

BRASIL. Portaria $n^{\circ} \mathbf{2 . 8 0 3}$ de 19 de novembro de 2013. Redefine a amplia o Processo Transexualizador no SUS. Diário Oficial da União, Brasília, nov 2013.

BRASIL. Portaria $\mathbf{n}^{\mathbf{2}} \mathbf{2 . 8 3 6}$, de $\mathbf{1}^{\mathbf{0}}$ de Dezembro de 2011. Institui o Plano Nacional de Saúde Integral LGBT. Diário Oficial da União, Brasília, dez 2011.

BRASIL. Portaria $n^{\circ} 1.820$ de 13 de agosto de 2009. Dispõe sobre os direitos e deveres dos usuários da saúde. Diário Oficial da União, Brasília, ago 2009.

BRASIL. Secretaria Especial dos Direitos Humanos. Anais da Conferência Nacional de Gays, Lésbicas, Bissexuais, Travestis e Transexuais - GLBT. Direitos Humanos e Políticas Públicas: o caminho para garantir a cidadania 
GLBT. Brasília, 2008.

CÂMARA DOS DEPUTADOS. Projeto de Decreto Legislativo $\mathbf{n}^{0} 234$ de 2011. Susta a aplicação do parágrafo único do Art. $3^{\circ}$ e o Art. $4^{\circ}$, da Resolução do Conselho Federal de Psicologia n ${ }^{\circ}$ 1/99 de 23 de Março de 1999, que estabelece normas de atuação para os psicólogos em relação à questão da orientação sexual.

CIRILO, Elisabete Gaidei Arabage; MIRANDA, Michelle Machado. O reconhecimento da identidade de gênero e a internação hospitalar de travestis e transexuais no SUS. Revista da Defensoria Pública, v. 5, n. 1, 2012.

GUARANHA, Camila. O Desafio da Equidade e da Integralidade: Travestilidades e Transexualidades no Sistema Único de Saúde. 2014. Dissertação (Mestrado em Psicologia) Universidade Federal do Rio Grande do Sul, Porto Alegre.

MULLER, Magnor Ildo; KNAUTH, Daniela Riva. Desigualdades no SUS: o caso do atendimento às travestis é 'babado'. Cadernos EBAPE. BR, v. 6, no 2, p. $1-14,2008$.

ONOCKO-CAMPOS, Rosana Teresa; FURTADO, J. P. Narrativas: apontando alguns caminhos para sua utilização na pesquisa qualitativa em Saúde. In: ONOCKO-CAMPOS, Rosana Teresa; FURTADO, Juarez Pereira; PASSOS, Eduardo; BENEVIDES, Regina. (Org.). Pesquisa Avaliativa em Saúde Mental: desenho participativo e efeitos da narratividade. São Paulo: Aderaldo \& Rothschild Editores, 2008, p. 321 - 334. 